\title{
THE RELATIONSHIP BETWEEN CUSTOMER SATISFACTION AND SECURITY TOWARD TRUST AND ITS IMPACT ON REPURCHASE INTENTION (SURVEY ON CUSTOMER OF ELEVENIA ONLINE WEBSITE)
}

\author{
Mohamad Rizan \\ Faculty of Economics State University of Jakarta \\ e-mail:mohamadrizan72@unj.ac.id \\ Kemal Abu Bakar \\ Faculty of Economics State University of Jakarta \\ e-mail: kemkems0910@gmail.com \\ Basrah Saidani \\ Faculty of Economics State University of Jakarta \\ e-mail: basrahsaidani@unj.ac.id
}

\begin{abstract}
The purpose of this research are to: examine empirically the effect of customer satisfaction to trust on customer, the impact of security to trust on customer, the impact of the customer satisfaction to repurchase intention on customer, the effect of security to repurchase intention on customer, the effect of trust to repurchase intention on customer, the effect of customer satisfaction to repurchase intention through trust as intervening variable on customer, the effect of security to repurchase intention through trust as intervening variable on customer of Elevenia website online. This research used survey methods for collecting data. The object of this research is 200 respondents who had purchased in Elevenia website online for a period of one year backward. This research used SPSS software version 22 and SEM (Structural Equation Modeling) LISREL version 8.7 for data analysis. Hypothesis testing showed that: the customer satisfaction has a positive effect and significance on trust, the security has a positive effect and significance on trust, the customer satisfaction has a positive effect and significance on repurchase intention, the security has a positive effect and significance on repurchase intention, the customer satisfaction has a positive effect and significance on repurchase intention through trust as intervening variable and the security has a positive effect and significance on repurchase intention through trust as intervening variable.
\end{abstract}

Keywords: Customer Satisfaction, Security, Trust, Repurchase Intention. 


\section{PENDAHULUAN}

Pada era globalisasi ini, kebutuhan konsumsi internet di Indonesia kini tengah berkembang sangat pesat. Tingkat persaingan yang semakin tinggi juga mendorong perusahaan untuk menentukan keputusan untuk memasarkan produknya. Dengan begitu, dibutuhkan sarana yang tepat untuk dunia pemasarannya. Melalui e-commerce, pemasaran kepada konsumen pada umumnya beroperasi berdasarkan prinsip pemasaran massa dan pemasaran ke bisnis terutama menyibukkan diri dengan masalah untuk membangun tenaga pemasaran yang terbaik. Untuk memanfaatkan kemajuan teknologi guna menunjang keunggulan dari suatu perusahaan harus dilakukan dengan kebijakan yang terfokus pada metode pemasaran pada perusahaan, salah satunya yaitu dengan melalui e-commerce.

Apalagi, pertumbuhan pangsa pasar e-commerce juga sudah tidak dapat diragukan lagi. Di Indonesia sendiri, data menurut APJII (Asosiasi Penyelenggara Jasa Internet Indonesia), pada tahun 2015 tercatat jumlah pengguna internet telah mencapai angka 88,1 juta orang yang menggunakan pengguna aktif atau sekitar $30 \%$ dari total penduduk di Indonesia. Angka tersebut naik dari 71,2 juta di tahun sebelumnya. Pertumbuhan tersebut juga didukung dengan data dari Menkominfo yang menyebutkan bahwa nilai transaksi e-commerce pada tahun 2013 mencapai angka Rp130 triliun. Ditambah lagi, penjualan B2C e-commerce Indonesia menempati posisi ke 4 di AsiaPasifik di bawah Cina, Jepang, Korea dan India. Data tersebut menunjukkan bahwa potensi e-commerce di Indonesia masih sangat potensial.

Namun, ketertarikan orang Indonesia untuk berbelanja toko online ternyata belum seutuhnya besar. Menurut majalah Marketeers, masih banyak masyarakat Indonesia yang belum tertarik melakukan belanja secara online. Hanya sekitar 19,6\% perempuan dan 12,2\% laki-laki dalam data Marketeers yang berani untuk berbelanja dan melakukan transaksi di e-commerce. Beberapa kendala dan keluhan yang dirasakan oleh para netizen yang belum mau berbelanja di $e$ commerce yaitu adanya perbedaan antara gambar produk di website dengan barang yang diterima, waktu pengantaran yang lama hingga penipuan yang dilakukan toko online kepada konsumen. 
Berdasarkan data yang dilansir oleh sharingvision.com, diketahui bahwa transaksi pembayaran yang paling diminati oleh konsumen saat membeli secara online adalah melalui ATM. Kemudian diikuti oleh Cash On Delivery (COD), Transfer melalui kantor cabang bank, Internet Banking, kartu kredit, kartu debit dan PayPal dengan persentase transaksi paling banyak dilakukan adalah sekitar Rp1.000.000 - Rp5.000.000, yaitu sebesar 46\%. Akan tetapi, masih banyakkonsumen yang belum percaya pada transaksi online. Tidak ada atau kurang jelasnya peraturan hukum yang mengatur tentang keamanan dalam bertransaksi online menjadi salah satu penyebab ketidakpercayaan tersebut. Selain itu, masyarakat Indonesia juga masih khawatir terhadap adanya cyber attack yang membuat mereka enggan bertransaksi secara online.

Persaingan pasar e-commerce yang semakin ketat membuat Elevenia harus menciptakan inovasi-inovasi yang mampu bersaing dengan kompetitornya. Berikut adalah data tentang situs e-commerce paling favorit berdasarkan hasil polling statistik dari selular.co.id yang dikutip oleh afrid-fransisco.com.

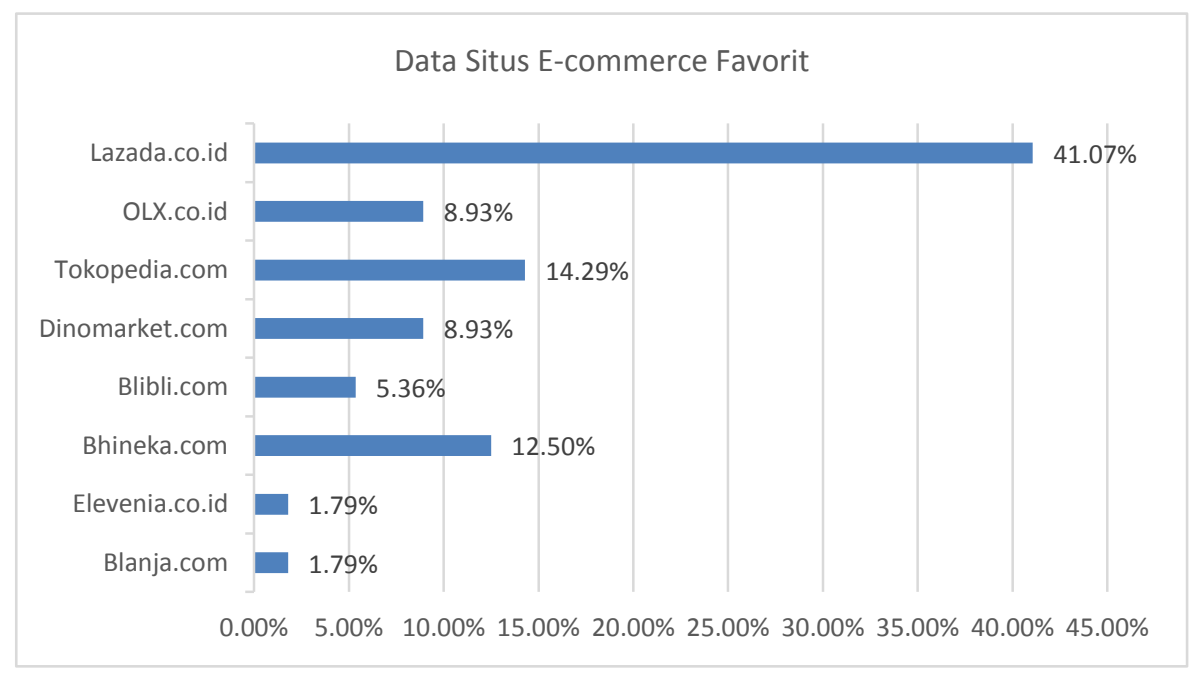

\section{Gambar 1. Data Situs E-Commerce Favorit di Indonesia}

Sumber : http://www.afrid-fransisco.com/2015

Dapat dilihat dari grafik tersebut bahwa Elevenia masih kurang favorit yang digunakan oleh para konsumen untuk berbelanja online dengan persentase hanya sebesar 1,79\% saja. Selain itu, ternyata Elevenia juga tidak luput dari berbagai kritik dari para konsumen.

Berdasarkan kritikan dari para konsumen Elevenia di beberapa website atau surat baca, keluhan keluhan negatif banyak ditujukan kepada pihak bisnis 
online ini. Diantaranya barang yang dipesan oleh konsumen tidak sesuai dengan yang berada di website. Setelah itu, konsumen mengeluhkan yang mereka rasakan dengan menghubungi Customer Service Elevenia. Pada awalnya keluhan tersebut dilayani dengan baik, akan tetapi tetap tidak ada kejelasan tentang barang yang mereka terima akan diganti atau tidak. Ketidakjelasan ketersediaan barang ini membuat customer ingin me-refund pesanan tersebut namun dengan proses yang rumit dan panjang. Bahkan setelah diurus dengan proses yang rumit dan panjang tersebut, pelanggan tetap tidak mendapat kepastian untuk menerima kembali uang yang mereka bayarkan. Selain itu pihak Elevenia pun terkesan angkat tangan dan Customer Service menjadi sama sekali tidak ramah dan terkesan ngotot. Maka dari itu rata-rata konsumen yang mengalami kekecewaan semacam ini tidak ingin lagi menggunakan jasa Elevenia ketika mereka ingin berbelanja online kembali.

Selain data mengenai kritikan negatif dari para netizen tentang Elevenia, peneliti juga melakukan pra-penelitian dengan menggunakan kuesioner yang dilakukan kepada 132 konsumen yang pernah berbelanja secara online melalui toko online Elevenia. Konsumen tersebut pernah merasakan pengalaman berbelanja di Elevenia. Dapat disimpulkan bahwa konsumen yang berniat untuk berbelanja kembali di Elevenia hanya sebesar 33\% sedangkan konsumen yang tidak berniat untuk berbelanja lagi adalah sebesar 67\%. Diagram tersebut menunjukkan bahwa konsumen enggan untuk kembali berbelanja di toko online Elevenia. Hal ini dikarenakan konsumen masih kurang percaya dengan pelayanan customer service yang masih buruk, sistem pengembalian (refund) yang rumit serta kurangnya komunikasi antara Elevenia dengan penjual barang sehingga menyebabkan ketidakjelasan informasi mengenai barang yang akan dipesan oleh pembeli.

\section{Rumusan Permasalahan}

Dengan latar belakang diatas, peneliti memfokuskan masalah yang dapat dirumuskan sebagai berikut:

1. Bagaimana deskripsi dari kepuasan pelanggan, keamanan, kepercayaan dan minat membeli kembali pada toko online Elevenia? 
2. Apakah kepuasan pelanggan berpengaruh positif dan signifikan terhadap kepercayaan pada toko online Elevenia?

3. Apakah keamanan berpengaruh positif dan signifikan terhadap kepercayaan pada toko online Elevenia?

4. Apakah kepercayaan berpengaruh positif dan signifikan terhadap minat membeli kembali pada toko online Elevenia?

5. Apakah kepuasan pelanggan berpengaruh positif dan signifikan terhadap minat membeli kembali pada toko online Elevenia?

6. Apakah keamanan berpengaruh positif dan signifikan terhadap minat membeli kembali pada toko online Elevenia?

7. Apakah kepuasan pelanggan berpengaruh positif dan signifikan terhadap minat membeli kembali) dengan kepercayaan sebagai intervening pada toko online Elevenia?

8. Apakah keamanan berpengaruh positif dan signifikan terhadap minat membeli kembali dengan kepercayaan sebagai intervening pada toko online Elevenia?

\section{Tujuan Penelitian}

Tujuan yang ingin dicapai dalam penelitian ini adalah sebagai berikut:

1. Untuk mengetahui deskripsi dari kepuasan pelanggan, keamanan yang dirasakan, kepercayaan dan minat membeli kembali pada toko Online Elevenia.

2. Untuk mengetahui pengaruh signifikansi kepuasan pelanggan terhadap kepercayaan pada toko Online Elevenia.

3. Untuk mengetahui pengaruh signifikansi keamanan terhadap kepercayaan pada toko Online Elevenia.

4. Untuk mengetahui pengaruh signifikansi kepercayaan terhadap minat membeli kembali pada toko Online Elevenia.

5. Untuk mengetahui pengaruh signifikansi kepuasan pelanggan terhadap minat membeli kembali pada toko Online Elevenia.

6. Untuk mengetahui pengaruh signifikansi keamanan terhadap minat membeli kembali pada toko Online Elevenia. 
Jurnal Riset Manajemen Sains Indonesia (JRMSI) | Vol 6, No. 2, 2015

7. Untuk mengetahui pengaruh signifikansi kepuasan pelanggan terhadap minat membeli kembali dengan variabel kepercayaan sebagai intervening pada toko Online Elevenia.

8. Untuk mengetahui pengaruh signifikansi keamanan terhadap minat membeli kembali dengan variabel kepercayaan (trust) sebagai intervening pada toko Online Elevenia.

\section{KAJIAN TEORI}

\section{Minat Membeli Kembali}

Helier et al dalam Kyauk dan Chaipoopirutana (2014) mendefinisikan bahwa repurchase intention adalah pengakuan individu untuk membeli kembali produk tertentu atau jasa dari bisnis atau produk yang sama, menggunakan informasi mereka sendiri berdasarkan keadaan saat ini dan kemungkinan yang dapat di pertimbangkan dan juga repurchase intention akan meningkatkan perilaku konsumen untuk terus menerus membeli pada masa depan.

Mowen \& Minor dari Myra Johana P (2006) menyatakan bahwa setelah konsumen menerima dan merasakan manfaat ataupun nilai dari suatu produk, konsumen tersebut sudah memiliki perilaku loyal, rasa puas dan komitmen terhadap produk itu, dimana pada akhirnya dapat menimbulkan tujuan untuk membeli ulang produk itu dimasa yang akan datang.

Menurut Kinnear dan Taylor dalam Saidani dan Arifin (2012) mengatakan bahwa minat beli adalah tahap kecenderungan responden untuk bertindak sebelum keputusan membeli benar-benar dilaksanakan. Terdapat perbedaan antara pembelian aktual dan minat membeli kembali. Bila pembelian aktual adalah pembelian yang benar-benar dilakukan oleh konsumen, maka minat membeli kembali adalah niat untuk melakukan pembelian kembali pada kesempatan mendatang. Menurut Hellier et al dalam Johana (2006) pembelian ulang dipengaruhi oleh beberapa faktor, diantaranya: Brand Preference, Perceived Value, Perceived Quality, dan Perceived Price. 


\section{Kepercayaan}

Kepercayaan atau trust merupakan salah satu aspek yang penting bagi konsumen dalam memilih dan memutuskan produk yang akan dibeli atau dikonsumsi. Kepercayaan akan membuat konsumen merasa aman dan nyaman dalam menggunakan sebuah produk. Menurut Morgan dan Hunt dalam Kuscu

dan Ozcam (2014), kepercayaan didefinisikan sebagai kenyamanan dalam pertukaran antara reabilitas dan integritas dan juga diposisikan sebagai variabel pengembangan dari hubungan jangka panjang.

Trust merupakan faktor penting dalam hubungan antara pembeli dan penjual dan dalam keputusan konsumen untuk membeli secara online pada toko online (ecommerce) menurut Zhou et al dalam Meskaran et al (2013). Selain itu, dalam konteks bisnis online atau e-commerce, kepercayaan meliputi keyakinan konsumen dan ekspektansi pada karakter penjual online menurut McKnight dalam Meskaran et al (2013).

Menurut Jarvenpaa dan Tractinsky dalam Bulut (2015) dikatakan bahwa kepercayaan dalam berbelanja secara online merupakan keinginan konsumen untuk mempercayakan penjual dan mengambil tindakan dalam keadaan dimana tindakan tersebut membuat konsumen mudah terpengaruhi oleh penjual.

Doney dan Cannon, Rousseau et al dalam Mohmed et al (2013) mendefinisikan kepercayaan sebagai posisi psikologis yang meliputi keinginan untuk menerima sensitivitas berdasarkan ekspektasi positif pada keinginan pembeli atau perilaku pembeli. Menurut Bhattacherjee dalam Iqbal (2012) ada 3 dimensi dalam kepercayaan atau trust, yaitu diantaranya : Integrity, Benevolence, dan Ability.

\section{Kepuasan Pelanggan}

Kepuasan pelanggan merupakan faktor penentu keberhasilan seorang pebisnis atau perusahaan dalam memenuhi kebutuhan konsumen. Menurut Armstrong dan Keller (2015), kepuasan tergantung dari ekspektasi pembeli. Bila performa produk atau jasa tidak sesuai dengan ekspektasi pembeli, maka konsumen akan merasa kecewa. Bila 
performa seimbang dengan ekspektasi, maka konsumen akan puas. Bila performa melebihi ekspektasi, maka konsumen akan merasa sangat puas.

Menurut Peter dan Olson (2010), kepuasan adalah konsep kritikal dalam pengetahuan pemasaran dan riset konsumen. Dalam teori bila konsumen merasa puas, maka mereka akan terus melanjutkan untuk membeli suatu produk atau jasa tersebut dan memberitahu pengalaman kepuasan mereka kepada orang lain. Bila mereka tidak puas, maka mereka akan mengganti produk dan memberi complain kepada pabrik, ritel, dan konsumen lain.

Sependapat dengan Amstrong dan Keller menurut Aritonang (2007), kepuasan pelanggan didefinisikan sebagai hasil penilaian pelanggan terhadap apa yang diharapkannya dengan membeli dan mengkonsumsi suatu produk. Kotler dan Keller (2015) mendefinisikan bahwa kepuasaan adalah perasaan seseorang atas kesenangan atau kekecewaan yang dihasilkan dari membandingkan kinerja dan hasil kualitas produk yang berhubungan dengan ekspektasi yang diharapkannya. Menurut Jiradilok et al (2014), kepuasan konsumen diukur melalui 3 indikator diantaranya: Information quality, System quality, dan Service quality.

\section{Keamanan}

Menurut Suh dan Han dalam Ozguven (2011), keamanan merupakan perhatian dasar dari konsumen apakah ia ingin tetap berbelanja melalui internet. Kegagalan dalam menempatkan keamanan yang kurang berpengalaman dapat menjadi ukuran dalam memastikan kenyamanan data konsumen yang merupakan batasan yang paling utama dalam perkembangan bisnis online menurut Furnell dan Karweni dalam Ozguven (2011).

Matic dan Vojvodic (2014) mengemukakan bahwa keamanan dan privasi dalam konteks bisnis online telah menjadi isu yang penting bagi penjual atau retailer online untuk mempertahankan konsumen. Terlebih lagi, keamanan dan privasi juga telah menjadi perhatian yang diposisikan sebagai batasan utama dalam penggunaan ecommerce. Menurut Culnan et al dalam Trong et al (2014), jika dibandingkan dengan ekonomi secara tradisional, konsumen yang membeli barang atau produk secara online akan lebih waspada pada kebutuhan privasi atau keamanan dan lebih fokus agar tidak terjadi hal-hal tidak menyenangkan seperti insfrastruktur yang buruk, kurangnya rasa percaya dan privasi serta keamanan yang seringkali menyebabkan terjadinya penurunan pada penjualan. 
Miyazaki dan Fernandez dalam Matic dan Vojvodic (2014) juga menambahkan bahwa persepsi resiko berkaitan dengan privasi dan keamanan dalam internet telah diidentifikasikan sebagai sebuah isu penting bagi pengguna teknologi internet baik pengguna baru maupun pengguna yang telah berpengalaman. Rahman dan Han (2011) berpendapat bahwa ada empat persyaratan dalam sistem keamanan, diantaranya, Privacy, Integrity, Authentication, dan Non-repudiation.

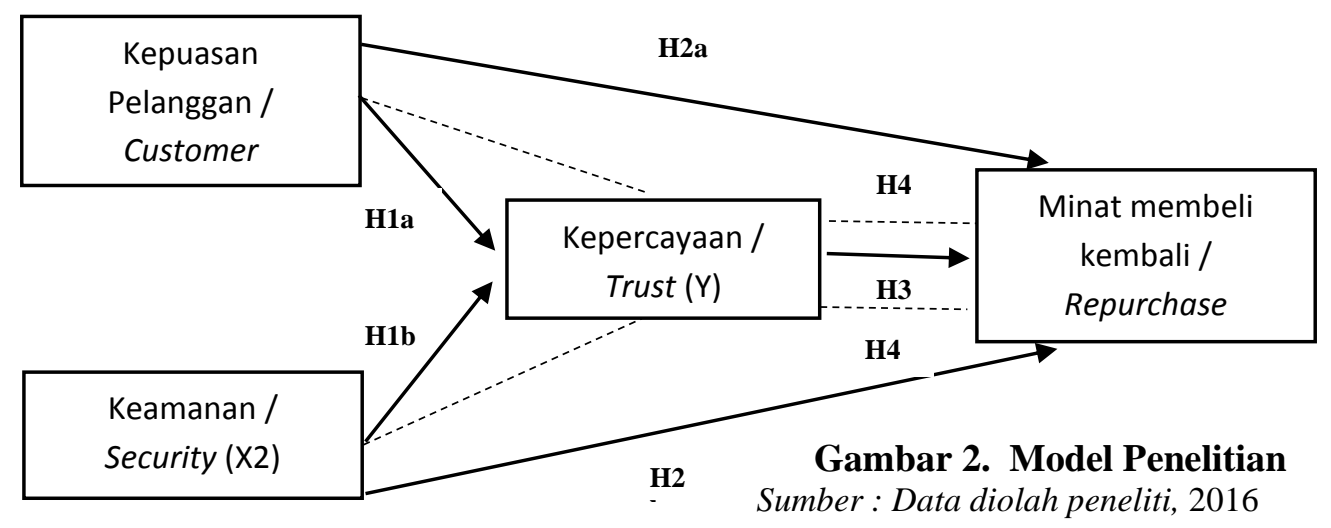

Berdasarkan kajian teori dan kerangka pemikiran yang telah dijelaskan diatas, maka hipotesis pada penelitian ini adalah:

H1a: Kepuasan pelanggan (customer satisfaction) berpengaruh positif dan signifikan terhadap kepercayaan (trust).

H1b: Keamanan (security) berpengaruh positif dan signifikan terhadap kepercayaan (trust).

H2a: Kepuasan pelanggan (customer satisfaction) berpengaruh positif dan signifikan terhadap minat membeli kembali (repurchase intention).

H2b: Keamanan (security) berpengaruh positif dan signifikan terhadap minat membeli kembali(repurchase intention).

H3: Kepercayaan (trust).berpengaruh positif dan signifikan terhadap minat membeli kembali (repurchase intention).

H4a: Kepuasan pelanggan (customer satisfaction) berpengaruh positif dan signifikan terhadap minat membeli kembali(repurchase intention)dengan kepercayaan (trust) sebagai intervening.

H4b: Keamanan (security) berpengaruh positif dan signifikan terhadap minat membeli kembali (repurchase intention)dengan kepercayaan (trust) sebagai intervening. 


\section{METODOLOGI PENELITIAN}

Metode penelitian yang digunakan adalah penelitian kuantitatif. Menurut Sugiyono (2012), penelitian kuantitatif adalah penelitian yang bersifat deskriptif dan cenderung menggunakan analisis pendekatan induktif. Penelitian kuantitatif adalah penelitian yang menitik beratkan pada pengukuran dan analisis hubungan sebab akibat setiap variabel.

Metode pengumpulan data menggunakan metode survei yaitu dengan penyebaran kuesioner yang telah terstruktur yang diberikan kepada responden yang dirancang untuk mendapatkan informasi yang lebih spesifik menurut Malhotra (2009).

\section{Populasi dan Sampel}

Menurut Sugiyono (2013), populasi adalah wilayah generalisasi yang terdiri atasobjek atau subjek yang memiliki kualitas dan karakteristik tertentu yang ditetapkan oleh peneliti untuk dipelajari dan kemudian ditarik kesimpulannya. Populasi pada penelitian ini mengacu pada pelanggan yang sudah pernah berkunjung ke website Elevenia serta pernah membeli barang di Toko Online Elevenia. Jenis populasi yang akan diteliti adalah populasi infinite, yaitu objek dengan ukuran yang tidak terhingga (infinite), yang karakteristiknya dikaji atau diuji melalui sampling karena peneliti tidak mengetahui jumlah pasti pelanggan yang pernah berbelanja di Toko online Elevenia.

Menurut Hair et.al (2010) ada beberapa saran yang dapat digunakan sebagai pedoman dalam menentukan ukuran sampel dalam analisis SEM salah satunya adalah ukuran sampel 100 - 200 untuk teknik estimasi maximum likelihood (ML). Berdasarkan teori tersebut maka peneliti menetakan jumlah sampel sebanyak 200 orang responden.

Instrumen menggunakan skala likert, $1=$ sangat tidak setuju, $2=$ tidak setuju, $3=$ biasa saja, $4=$ setuju dan $5=$ sangat setuju. Metode sampling yang digunakan dalam penelitian ini adalah purposive sampling. Menurut Sekaran (2007), purposive sampling adalah peneliti memperoleh informasi dari mereka yang paling siap dan memenuhi beberapa kriteria yang dibutuhkan dalam memberikan informasi. Alat analisis data adalah SPSS 22.00 dan LISREL 8.7 


\section{HASIL DAN PEMBAHASAN}

\section{Analisis Deskriptif}

Secara umum, hasil penilaian atau evaluasi setiap konsumen toko online Elevenia sebagai responden pada penelitian ini mayoritas positif. Sikap responden pada kepuasan pelanggan toko online Elevenia mayoritas positif. Pada ketiga dimensi persentase responden merespon positif $>50 \%$ artinya konsumen Elevenia merasa puas ketika berbelanja di toko online Elevenia. Meskipun terdapat pernyataan yang direspon negatif yaitu beberapa pernyataan pada dimensi information quality. Artinya konsumen Elevenia belum merasakan adanya kualitas informasi yang baik yang diberikan pada toko online Elevenia.

Pada variabel keamanan diukur dengan empat dimensi. Pada keempat dimensi persentase responden merespon positif $>50 \%$ artinya konsumen Elevenia merasa aman saat berbelanja pada website Elevenia secara online dan mau memberikan informasiinformasi umum ketika memesan barang pada website.

Pada variabel kepercayaan diukur dengan tiga dimensi. Pada ketiga dimensi persentase responden merespon positif $>50 \%$ artinya konsumen merasakan adanya kemampuan, kebaikan dan integritas yang ditunjukkan oleh Elevenia. Meskipun terdapat pernyataan yang direspon negatif yaitu beberapa pernyataan pada dimensi ability. Artinya konsumen belum merasakan kemampuan yang cukup baik oleh Elevenia dalam menyediakan varian barang untuk berbagai macam kalangan.

Pada variabel minat membeli kembali diukur dengan empat dimensi. Pada keempat dimensi responden merespon positif $<50 \%$ artinya sebagian besar konsumen Elevenia belum memiliki minat untuk berbelanja atau membeli kembali barang di toko online Elevenia. Kemudian terdapat pernyataan yang direspon negative yaitu beberapa pernyataan pada dimensi brand preference $>30 \%$ responden merespon negatif, artinya konsumen menganggap bahwa merek Elevenia masih belum bisa mengalahkan kompetitornya. Selanjutnya pada dimensi perceived value > 50\% responden merespon negative, artinya nilai pada Elevenia khususnya untuk sumber daya manusianya belum bisa diterima oleh konsumen dengan baik. 


\section{Uji Instrumen}

Hasil dari pengujian instrumen validitas melibatkan 50 responden dengan signifikansi sebesar 0.05 (5\%). Kemudian pada tes $\mathrm{KMO}$ and Bartlett seluruh variabel telah mencapai nilai $>0.5$.

Tabel 1. Hasil Uji Validitas

\begin{tabular}{cccc}
\hline Variabel & $\begin{array}{c}\text { Jumlah Item } \\
\text { Sebelum Diuji }\end{array}$ & $\begin{array}{c}\text { Jumlah Item Tidak } \\
\text { Valid }\end{array}$ & $\begin{array}{c}\text { Jumlah Item } \\
\text { Valid }\end{array}$ \\
\hline Kepuasan Pelanggan & 15 & 0 & 15 \\
\hline Keamanan & 8 & 0 & 8 \\
\hline Kepercayaan & 13 & 0 & 13 \\
\hline Minat Membeli Kembali & 17 & 0 & 17 \\
\hline
\end{tabular}

Sumber : Data diolah oleh peneliti, 2016.

Berdasarkan Tabel 1 dapat dilihat bahwa seluruh item pernyataan untuk variabel kepuasan pelanggan, keamanan, kepercayaan dan minat membeli kembali dinyatakan valid karena telah memenuhi syarat yaitu hasil nilai KMO $>0.5$. Untuk variabel kepuasan pelanggan, jumlah item sebelum diuji berjumlah 15 butir dan seluruh item tersebut valid. Begitu pula dengan variabel keamanan dan kepercayaan dengan jumlah item sebelum diuji masing-masing berjumlah 8 butir dan 13 butir. Seluruh item tersebut juga dinyatakan valid. Sedangkan variable minat membeli kembali dengan jumlah item sebelum diuji berjumlah 17 butir dan seluruh item tersebut valid. Sehingga jumlah item yang valid dan dapat digunakan pada penelitian ini adalah sebanyak 53 butir pernyataan.

Uji reliabilitas adalah pengujian untuk mengetahui seberapa konsisten pengukuran terhadap instrumen yang diukur. Kriteria pengujian reliabilitas adalah jika nilai Cronbach's Alpha > 0,6, maka instrumen penelitian dapat dikatakan reliabel, sedangkan jika nilai Cronbach's Alpha $<0,6$, maka instrumen penelitian dikatakan tidak reliabel.

Hasil uji reliabilitas untuk masing-masing variabel dapat dilihat pada Tabel 2 berikut ini :

Tabel 2. Hasil Uji Reliabilitas

\begin{tabular}{ccc}
\hline Variabel & Cronbach's Alpha & Keterangan \\
\hline Kepuasan Pelanggan & 0,854 & Reliabel \\
\hline Keamanan & 0,711 & Reliabel \\
\hline Kepercayaan & 0,888 & Reliabel \\
\hline Minat Membeli Kembali & 0,835 & Reliabel \\
\hline : Data diolah oleh peneliti, 2016 & &
\end{tabular}


Pada Tabel 2, hasil uji reliabilitas untuk masing-masing variabel dengan menggunakan teknik Cronbach's Alpha, terlihat bahwa nilai Cronbach's Alpha > 0,6; untuk variabel kepuasan pelanggan, keamanan, kepercayaan dan minat membeli kembali secara berurutan adalah sebesar 0,$854 ; 0,711 ; 0,888 ; 0,835$. Dengan demikian, keempat variabel tersebut dikatakan reliabel karena telah memenuhi syarat.

\section{Fitted Model SEM}

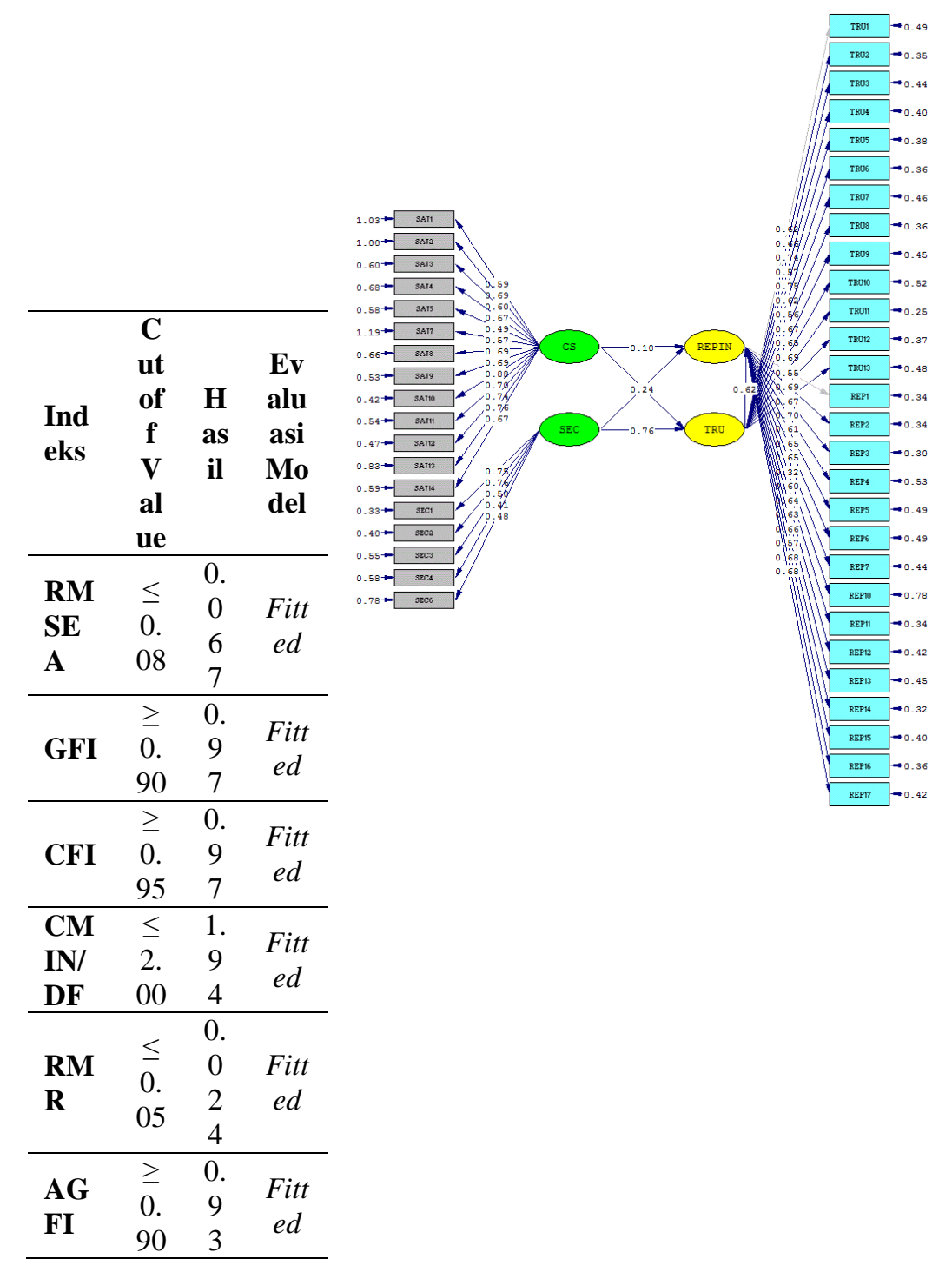

Gambar 3. Fitted Model SEM

Sumber : Data diolah oleh peneliti, 2016.

Uji kecocokan model (goodness of fit test) yaitu dengan melihat kepada nilai-nilai kriteria yang telah ditetapkan untuk mengetahui apakah full model SEM sudah fit atau 
belum. Nilai RMSEA sebesar 0.02, GFI sebesar 0.94, CFI sebesar 0.95, CMIN/DF sebesar 1.40, RMR sebesar 0.03, dan AGFI sebesar 0.91. Berdasarkan hasil tersebut model tujuh alat ukur (P, RMSEA, GFI, CFI, RMR, CMIN/DF, dan AGFI) menunjukkan angka yang baik sesuai dengan kriteria indeks, hal ini mengindikasikan bahwa model sudah fit dengan data yang ada.

\section{Uji Hipotesis}

Tabel 3. Model Persamaan Struktural

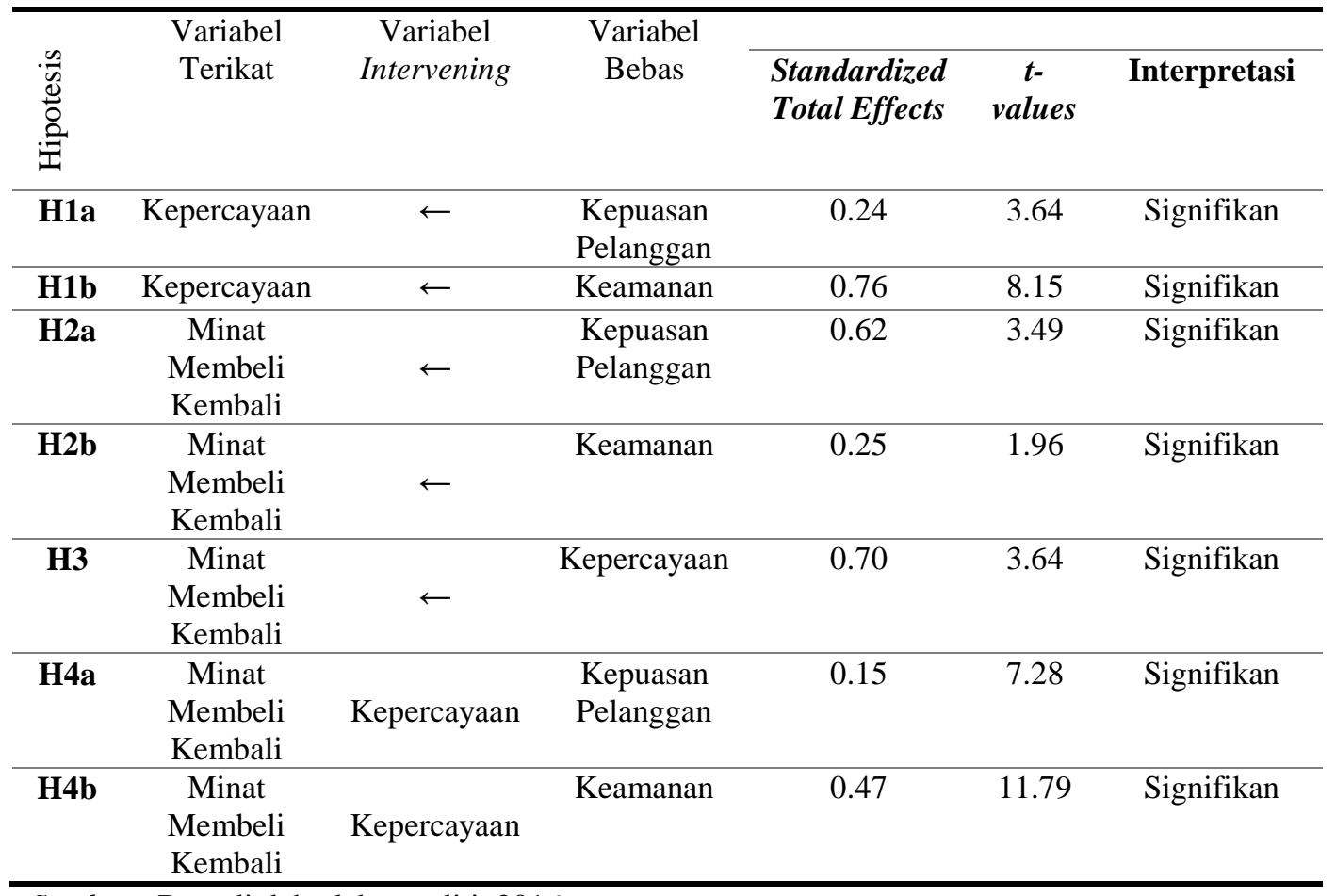

Sumber : Data diolah oleh peneliti, 2016.

Berdasarkan tabel 3 maka dapat dilakukan pengujian hipotesis dalam penelitian ini, yaitu sebagai berikut :

1. Variabel kepuasan pelanggan terhadap kepercayaan pada model ini memiliki nilai standardized total effects sebesar 0.24 , sehingga hipotesis 1a yang menyatakan kepuasan pelanggan terhadap kepercayaan berpengaruh positif sebesar $24 \%$ dan dapat diterima.

2. Variabel keamanan terhadap kepercayaan pada model ini memiliki nilai standardized total effects sebesar 0.76 , sehingga hipotesis $1 \mathrm{~b}$ yang menyatakan keamanan terhadap kepercayaan berpengaruh positif sebesar $76 \%$ dan dapat diterima.

3. Variabel kepuasan pelanggan terhadap minat membeli kembali pada model ini memiliki nilai standardized total effects sebesar 0.25 , sehingga hipotesis 2 a yang 
menyatakan kepuasan pelanggan terhadap minat membeli kembali berpengaruh positif sebesar $25 \%$ dapat diterima.

4. Variabel keamanan terhadap minat membeli kembali pada model ini memiliki nilai standardized total effects sebesar 0.70 , sehingga hipotesis $2 \mathrm{~b}$ yang menyatakan keamanan terhadap minat membeli kembali berpengaruh positif sebesar $70 \%$ dapat diterima.

5. Variabel kepercayaan terhadap minat membeli kembali pada model ini memiliki nilai standardized total effects sebesar 0.62 , sehingga hipotesis 3 yang menyatakan kepercayaan terhadap minat membeli kembali berpengaruh positif sebesar $62 \%$ dan dapat diterima.

6. Variabel kepuasan pelanggan terhadap minat membeli kembali melalui kepercayaan pada model ini memiliki nilai standardized total effects sebesar 0.15 , sehingga hipotesis 4a yang menyatakan kepuasan pelanggan terhadap minat membeli kembali berpengaruh positif sebesar 15\% yang dimediasi oleh kepercayaan dapat diterima.

7. Variabel keamanan terhadap minat membeli kembali melalui kepercayaan pada model ini memiliki nilai standardized total effects sebesar 0.47 , sehingga hipotesis $4 \mathrm{~b}$ yang menyatakan keamanan terhadap minat membeli kembali berpengaruh positif sebesar $47 \%$ yang dimediasi oleh kepercayaan dapat diterima.

\section{KESIMPULAN DAN SARAN}

\section{Kesimpulan}

Setelah menganalisis data primer mengenai kepuasan pelanggan dan keamanan terhadap kepercayaan serta dampaknya pada minat membeli kembali. Maka dapat diambil kesimpulan sebagai berikut :

1. H1a menyatakan bahwa kepuasan pelanggan berpengaruh positif dan signifikan terhadap kepercayaan pada konsumen toko online Elevenia diterima.

2. H1b menyatakan bahwa keamanan berpengaruh positif dan signifikan terhadap kepercayaan pada konsumen toko online Elevenia diterima.

3. H2a menyatakan bahwa kepuasan pelanggan berpengaruh positif dan signifikan terhadap minat membeli kembali pada konsumen toko online Elevenia diterima.

4. H2b menyatakan bahwa keamanan berpengaruh positif dan signifikan terhadap minat membeli kembali pada konsumen toko online Elevenia diterima. 
5. H3 menyatakan bahwa kepercayaan berpengaruh positif dan signifikan terhadap minat membeli kembali pada konsumen toko online Elevenia diterima.

6. H4a menyatakan bahwa kepuasan pelanggan berpengaruh positif dan signifikan terhadap minat membeli kembali yang dimediasi oleh kepercayaan pada konsumen toko online Elevenia diterima.

7. H4b menyatakan bahwa keamanan berpengaruh positif dan signifikan terhadap minat membeli kembali yang dimediasi oleh kepercayaan pada konsumen toko online Elevenia diterima.

\section{Saran}

Berikut adalah beberapa saran untuk toko online Elevenia :

a. Elevenia seharusnya meningkatkan kualitas dengan menciptakan rasa aman dan kepuasan kepada konsumen mereka. Faktor-faktor tersebut sangat penting bagi terciptanya rasa kepercayaan terhadap toko online Elevenia. Rasa aman seperti pembayaran di tempat (Cash On Delivery) serta peningkatan kepuasan seperti memberikan reward ketika konsumen berulang tahun.

b. Elevenia yang merupakan bagian dari PT XL Axiata dapat memanfaatkan customer base dari provider kartu XL untuk memberikan info-info menarik tentang Elevenia. Hal ini dilakukan guna meningkatkan promosi kepada pelanggan kartu XL.

c. Di tengah persaingan yang semakin ketat pada bisnis toko online saat ini, Elevenia masih tertinggal jauh dari para kompetitornya dalam segi penjualan. Hal ini disebabkan karena persaingan harga, kualitas produk dan juga pelayanan. Elevenia sebaiknya dapat memberikan keuntungan bagi para konsumennya dengan rutin memberikan voucher belanja gratis dan juga diskon-diskon yang akan menarik perhatian konsumen untuk berbelanja.

d. Sistem keamanan merupakan salah satu faktor yang penting bagi bisnis toko online. Dengan adanya sistem keamanan yang baik, maka konsumen akan dengan mudah mengakses jaringan website toko online tanpa khawatir terjadinya kerusakan sistem yang dapat mengganggu konsumen dalam berbelanja. Elevenia dapat kenyamanan 
akses yang lebih baik bagi para konsumen dengan meminimalisir terjadinya service timed out atau kesulitan akses website yang akan merugikan konsumen. Hal ini dapat dilakukan dengan memperbesar bandwith agar konsumen lebih nyaman dalam berbelanja karena tidak harus menunggu terlalu lama.

e. Elevenia seharusnya dapat menjangkau seluruh kalangan baik wanita maupun pria untuk meningkatkan penjualan. Elevenia dapat meningkatkan variasi barang yang dijual yang tidak hanya diperuntukkan untuk wanita dan pria dewasa saja tetapi juga untuk konsumen anak-anak, balita, remaja, dan juga para lansia. Dengan adanya variasi barang yang cukup banyak, Elevenia dapat menarik banyak konsumen dari kalangan manapun.

f. Dengan adanya masalah mengenai buruknya pelayanan customer service untuk mengatasi keluhan konsumen, Elevenia seharusnya mengadakan pelatihan untuk para customer service dan sumber daya manusianya agar lebih terampil dan handal dalam menghadapi dan menangani keluhan konsumen yang seringkali terjadi. Customer service Elevenia seharusnya bertugas untuk menerima keluhan dan menanggapi respon kepada konsumen dengan cepat.

\section{DAFTAR PUSTAKA}

Amstrong, Gary dan Philip Kotler. Marketing an Introduction Ch. 12. Pearson Education, Inc. 2015.

Aritonang R Lerbin R., Kepuasan Pelanggan:Pengukuran dan Penganalisisan Dengan SPSS. Penerbit PT Gramedia Pustaka Utama. 2007

Bulut, Zeki Atil. "Determinants of Repurchase Intention in Online Shopping: A Turkish Consumer's Perspective.” International Journal of Business and Social Science. 2015. Vol. 6. No. 10.

Fransisco, Afrid. Prediksi Trend Bisnis Toko Online. 2015. http://googleweblight.com/?lite_url=http://www.afridfransisco.com/2015/01/prediksi-trends-bisnis-toko-online (Diakses pada 28 Februari 2016)

Hair et.al, Multivariate Data Analysis, 7th Edition. Mcmillan New York. 2010. 
Hellier et al. "Customer Repurchase Intention: A General Structural Equation." European Journal of Marketing. 2003. Vol 37. No 11.

Iqbal et al. "Consumer Intention to Shop Online: B2C E-Commerce in Developing Countries." Middle-East Journal of Scientific Research. 2012. Vol 12. No 4.

Jiradilok, Taweerat et al. "The Impact of Customer Satisfaction on Online Purchasing: A Case Study Analysis in Thailand." Journal of Economics, Business and Management. 2014. Vol. 2. No. 1.

Johana P, Myra. Analisis Faktor-Faktor yang mempengaruhi minat membeli kembali. Skripsi: Pasca Sarjana Universitas Diponogoro. 2006.

Kompas. Pengguna Internet Indonesia Tembus 88 Juta. 2016. http://tekno.kompas.com/read/2015/03/26/14053597/Pengguna.Internet.In donesia.Tembus.88.Juta. (Diakses pada 28 Februari 2016)

Kotler, Philip dan Kevin L. Keller. Marketing Management 15th Edition. Pearson Global Edition. 2015.

Kuscu dan Ozcam. "Analyzing Factors Affecting Repurchase Intention During Gezi Park Brand Protests." European Journal of Business and Management. 2014.

Kyauk, Sai Tip dan Sirion Chaipoopirutana. "Factors Influencing Repuchase Intention: A Case Study of XYZ.com Online Shopping Website in Myanmar." International Conference on Trends in Economics, Humanities and Management. 2014.

Malhotra, Naresh K. Riset Pemasaran. Penerbit PT. Indeks. 2009.

Maulana, Jaya. Perkembangan E-Commerce di Indonesia. 2013. http://sharingvision.com/2013/10/perkembangan-e-commerce-diindonesia/ (Diakses pada 28 Februari 2016)

Matic, Matea dan Katjja Vojvodic. "Customer-Perceived Insecurity of Online Shopping Environment." International Review of Management and Marketing. 2014. Vol. 4. No. 1.

Meskaran et al. "Online Purchase Intention: Effects of Trust and Security Perception." Australian Journal of Basic and Applied Sciences. 2013. Vol 7. No. 6.

Mitra, Wyndo. Data Statistik Mengenai Pertumbuhan Pangsa Pasar ECommerce di Indonesia Saat ini. 2014. http://startupbisnis.com/data- 
statistik-mengenai-pertumbuhan-pangsa-pasar-e-commerce-di-indonesia$\underline{\text { saat-ini/ (Diakses pada } 28 \text { Februari 2016) }}$

Mohmed et al. "The Impact of Trust and Past Experience on Intention to Purchase in E-Commerce." International Journal of Engineering Research and Development. 2013. Vol 7.

Ozguven, Nihan. "Analysis of the Relationship Between Perceived Security and Customer Trust and Loyalty in Online Shopping." Chinese Business Review. 2011. Vol 10. No. 11.

Peter, J. Paul dan Jerry C. Olson. Consumer Behavior \& Marketing Strategy $9^{\text {th }}$ Edition Ch 16. The Mcgraw-Hill Company, Inc. 2010.

Rahman, Habibur dan Lili Han. "Customer Satisfaction in E-Commerce : A Case Study of China and Bangladesh." Master's Thesis in International Business 15 ECTS : University West. 2011.

Saidani, Basrah dan Samsul Arifin. "Pengaruh Kualitas Produk dan Kualitas Layanan Terhadap Kepuasan Konsumen dan Minat Beli Pada Ranch Market. Jurnal Riset Manajemen Sains Indonesia. 2012. Vol. 3 No. 1.

Sekaran, Uma. Research Method For Business (Metodologi Penelitian Untuk Bisnis), Edisi 4. Salemba Empat. 2007.

Sugiyono. Statistik untuk penelitian. Penerbit Alfabeta, 2012.

Trong, Van Hung et al. "Evaluating Factors Influencing Consumer Satisfaction towards Online Shopping in Vietnam." Journal of Emerging Trends in Computing and Information Sciences. 2014. Vol.5 No. 1. 